\title{
Psicologia Evolucionista: uma perspectiva em expansão
}

\author{
Gabriela Dal Forno Martins \\ Nelson Hauck Filho \\ Natália Luz Feeburg \\ Heitor Barcellos Ferreira Fernandes \\ Jean Carlos Natividade \\ Claudio Simon Hutz \\ Universidade Federal do Rio Grande do Sul
}

\begin{abstract}
Resumo
A Psicologia Evolucionista (PE) é um campo teórico da Psicologia cujo objetivo é entender a natureza humana à luz da perspectiva evolucionista do neodarwinismo. Apesar de ter surgido formalmente na década de 1980, a PE começou a se popularizar no Brasil apenas neste século. O objetivo do presente trabalho foi realizar uma investigação sistemática da produção acadêmica nacional na área até o momento, contrastando-a com a produção internacional no mesmo período. Para tanto, realizou-se uma revisão sistemática de literatura nas bases de dados: Biblioteca Virtual em Saúde, Banco de Teses da CAPES e PsycINFO. Utilizou-se a palavra-chave "Psicologia Evolucionista", e sua correspondente em inglês, e a busca abrangeu todo o período disponível nas bases até 2010. Os trabalhos nacionais foram classificados de acordo com a temática de estudo e o método empregado, enquanto os internacionais foram apenas contabilizados. Os resultados permitiram constatar que, apesar do crescimento do número de publicações tanto no Brasil como no exterior, ainda são poucos os estudos empíricos na área no país. A predominância, nos estudos nacionais, é de revisões não sistemáticas de literatura e de temas relacionados a aspectos gerais da perspectiva evolucionista. Ressalta-se a necessidade de novos estudos brasileiros, sobretudo investigações empíricas e nas áreas de personalidade e psicopatologia.
\end{abstract}

Palavras-chave: Psicologia Evolucionista, Revisão sistemática, Estudos brasileiros.

\section{Evolutionary Psychology: an expanding approach}

\begin{abstract}
Evolutionary Psychology (EP) is a broad theoretic field within Psychology that to understand human nature from the standpoint of evolutionary perspective of neo-Darwinism. Although its emergence dates back to the 1980's, EP has developed in Brazil only in this century. The aim of the present study was to review systematically the Brazilian scientific publications related to EP and compare them to the international publications in the same period. Therefore, a systematic review of the literature was carried out on the following databases: Virtual Health Library, CAPES Theses Database, and PsycINFO. Studies containing the keyword "Evolutionary Psychology" or its correspondent version in Portuguese were used. The search was carried out considering studies available on the databases until 2010. Brazilian publications were classified by subject matter and method employed, whereas frequencies by year were computed for international studies. Although results showed a growing number of publications related to EP as a general tendency, there were few empirical studies in the area in Brazil. Non-systematic reviews of the literature and studies on general aspects of the evolutionary approach comprised the major part of Brazilian publications. The need of further empirical studies in the area in Brazil, particularly investigations of issues related to personality and psychopathology, is highlighted.
\end{abstract}

Keywords: Evolutionary Psychology, Systematic review, Brazilian studies.

Endereço para correspondência: Gabriela Dal Forno Martins. Rua Gomes Jardim, 980, apt 208. Bairro Santana. Porto Alegre/RS, Brasil. CEP: 90620-130. E-mail: gdalfornomartins@gmail.com. 


\section{Psicología Evolucionista: una perspectiva en expansión}

\section{Resumen}

La Psicología Evolucionista (EP) es un campo teórico en psicología que pretende comprender la naturaleza humana a la luz de la perspectiva de la evolución del neo-darwinismo. Aunque haber surgido formalmente en 1980, la EP comenzó a popularizarse en Brasil sólo desde la década del 2000. El objetivo de este estudio fue realizar una investigación sistemática de la producción académica brasileña hasta ahora en esta área, contrastando ella con la producción internacional en el mismo período. Para este, se realizo una revisión sistemática de la literatura en las bases de datos: Biblioteca Virtual en Salud, base de datos de Tesis de la CAPES y PsycINFO. Se utilizo como palabra clave el termo en portugués Psicología Evolucionista, y su homólogo inglés, y la búsqueda se corrió teniendo en cuenta todo tiempo disponible en las bases hasta el 2010. Los trabajos brasileños fueron clasificados de acuerdo con el objetivo de los estudios y con los métodos empleados, mientras los internacionales fueran solo contabilizados. Los resultados mostraron que, aunque el aumento en el número de publicaciones tanto en Brasil como en el extranjero, aún existen pocos estudios empíricos en el área en Brasil. La predominancia de los estudios brasileños recae sobre revisiones sistemáticas de literatura y sobre temas relacionados con aspectos generales de la perspectiva evolucionista. Se acentúa la necesidad de nuevos estudios brasileños, sobremanera investigaciones empíricas y en las áreas de la personalidad y psicopatología.

Palabras clave: Psicología Evolucionista, Revisión sistemática, Estudios brasileños.

A Psicologia tem sido marcada por uma extensa discussão acerca dos métodos e dos modelos teóricos mais adequados para o estudo do comportamento, da emoção e da cognição humana (Marx \& Hillix, 2000). Dentre as diversas perspectivas existentes, uma delas vem ganhando espaço na ciência psicológica nacional e internacional nos últimos anos: a Psicologia Evolucionista (PE). A PE é uma vasta disciplina que abrange diversos modelos psicológicos explicativos, cujo objetivo comum é o de entender a natureza humana à luz da perspectiva evolucionista do neodarwinismo (Buss, 1995). Nesse sentido, antes de ser considerada uma área da Psicologia, pode ser entendida como uma abordagem epistemológica para a ciência psicológica - ou seja, uma metateoria (Buss, 1995).

É importante destacar, porém, que PE não é a única perspectiva que tem por objetivo explicar a mente e o comportamento humano a partir nas ideias de Darwin (1859/2010; 1872/2009). Vertentes como Sociobiologia, Ecologia do comportamento humano, Memética e Teoria da dupla herança também se fundamentam na Teoria da Evolução (Laland \& Brown, 2002; Yamamoto, 2009). No entanto, o diferencial da PE frente às outras abordagens está na incorporação de uma noção de mente modular como motor e alicerce para os comportamentos (Tooby \& Cosmides, 1992).
A PE propõe uma expansão da noção de adaptações, do biológico para o mental (Tooby \& Cosmides, 1992). O argumento central da PE é o seguinte: se são verdadeiras as premissas (1) que mecanismos mentais possuem um substrato fisiológico (ativações neurais), (2) que os comportamentos ocorrem em função dos mecanismos mentais, (3) que alguns comportamentos proporcionaram maiores vantagens adaptativas (maiores chances de sobreviver e reproduzir) que outros e (4) que a Seleção Natural proporcionou modificações na fisiologia dos organismos ao longo do tempo; então, a Seleção Natural foi/é responsável por moldar nossa mente. A conclusão derivada das premissas 1-4 sugere que nossos principais mecanismos mentais possuíram, em algum momento de nossa história filogenética, uma função adaptativa (Tooby \& Cosmides, 1992). Esses mecanismos funcionariam como módulos de domínio específico, integrados entre si, capazes de resolver problemas específicos encontrados por nossos ancestrais (Pinker, 1998).

$\mathrm{O}$ ambiente no qual viveram nossos ancestrais hominídeos tem sido denominado de Ambiente de Adaptação Evolutiva (AAE), cuja origem é estimada em mais de dois milhões de anos (Izar, 2009). Os modos de vida atuais, inteiramente dependentes de recursos como agricultura, pecuária, sociedades organizadas e a escrita não estavam presentes naquele 
período, havendo surgido há apenas $10 \mathrm{mil}$ anos atrás (Rodrigues, 2009). A estrutura modular da mente humana, dessa maneira, foi delineada tendo como fulcro as condições de sobrevivência e os problemas enfrentados previamente ao surgimento desses recursos, havendo um descompasso entre os módulos mentais fixados e os modos de vida atuais (Pinker, 1998). Por esse motivo, a literatura propõe dois níveis de compreensão sobre o funcionamento da mente humana (Buss, 1995): 1) nível distal, em que se busca compreender o funcionamento de mecanismos mentais a partir da função adaptativa que ele desempenhou no AAE, ou seja, a explicação última para o mecanismo (i.e., Por que tal mecanismo evoluiu?); e 2) nível proximal, em que se busca considerar a atual interação da pessoa com o meio à sua volta (i.e., Como tal mecanismo está funcionando?).

Esses níveis compreensivos sobre a mente e o comportamento humano reforçam a noção de metateoria da PE e propiciam a integração de variadas teorias explicativas, desde que elas sejam úteis dentro do plano de análise da PE. No entanto, essa amplitude da teoria não tem sido facilmente reconhecida no campo da Psicologia, uma vez que a história da PE tem sido marcada pela existência de muitos preconceitos e mal-entendidos, os quais se fundamentam principalmente em interpretações errôneas de estudos veiculados pela mídia (Santos \& Varella, 2007).

No Brasil, o reconhecimento da PE é permeado também por sua inserção bastante recente no campo psicológico. Foi somente em 2004, com a criação do Grupo de Trabalho em Psicologia Evolucionista da Associação Nacional de Pesquisa e Pós-graduação em Psicologia (ANPPEP), que a área ganhou maior visibilidade. Através desse grupo, as ideias da PE deram base para construção de um projeto de pesquisa nacional, atrelado ao Instituto Milênio do $\mathrm{CNPq}$, cujo tema foi: "O moderno e o ancestral: a contribuição da Psicologia Evolucionista para a compreensão dos padrões reprodutivos e de investimento parental humano". Esse projeto, coordenado pela Profa. Dra. Maria Emília Yamamoto, da Universidade Federal do Rio Grande do Norte, deu início a uma fase de produção intensa, culminando na publicação de estudos teóricos e empíricos em diferentes subáreas da Psicologia (ver, por exemplo, Yamamoto \& Seidl-de-Moura, 2010), bem como no primeiro compêndio da área em português (Otta \&Yamamoto, 2009).

Assim, considerando o caráter recente dessa abordagem à Psicologia, especialmente no Brasil, esse estudo teve como objetivo: realizar uma revisão sistemática da produção acadêmica relacionada à PE no Brasil, incluindo, simultaneamente, teses, dissertações e artigos científicos publicados e catalogados em bases de dados no país. Particularmente, buscou caracterizar a produção nacional em termos de seus aspectos temáticos e metodológicos, bem como contrastar a frequência de produção acadêmica do Brasil com a frequência de produção acadêmica internacional. Esse contraste foi realizado visando a identificar indicadores do surgimento da disciplina dentro e fora do país, e seus relativos padrões de expansão anual no número de estudos nesses contextos. Entende-se que um levantamento dessa natureza pode contribuir com um mapeamento do desenvolvimento científico da PE, bem como indicar tendências e sugerir direcionamentos para o futuro da Psicologia sob essa perspectiva.

\section{Método}

Foi realizada uma revisão sistemática da literatura sobre a PE, a partir de buscas em bases de dados. Para tanto, utilizaram-se como fontes de consulta as bases de dados brasileiras Biblioteca Virtual em Saúde (BVS-Psi) e o Banco de Teses da Capes, além da base de dados internacional PsycINFO (base de dados online da American Psychological Association). Foi realizada uma busca pela palavra-chave "Psicologia Evolucionista" nas bases nacionais e "Evolutionary Psychology" na base internacional. Essa palavra-chave poderia estar em qualquer campo do registro para que o trabalho fosse incluído no corpo de análise - nas palavras-chave, no título ou no resumo. A escolha pela palavra-chave foi feita com o intuito de restringir a busca somente aos artigos que de fato tinham como foco a investigação de fenômenos psicológicos à luz da PE, e não de outros fenômenos ou áreas afins, como a Etologia, Sociobiologia, Biologia Evolucionista etc. A busca internacional foi restrita a artigos publicados em periódicos científicos, enquanto a nacional incluiu teses e dissertações defendidas em instituições brasileiras. Em todas as bases de dados, foram 
registrados os trabalhos publicados até dezembro de 2010.

De posse desses registros, foram calculadas as frequências totais de artigos, teses e dissertações por ano em cada base de dados, incluindo os artigos internacionais. Em seguida, somente os artigos brasileiros foram categorizados quanto à sua natureza metodológica e à sua temática. As categorias temáticas foram estabelecidas a partir da classificação das palavras-chave desses trabalhos, sendo obtido um consenso dos pesquisadores deste estudo quanto à classificação. As categorias metodológicas e temáticas encontram-se nas Tabelas 1 e 2.

\section{Tabela 1 - Categorias Metodológicas Elaboradas para Classificação dos Estudos}

\begin{tabular}{|c|c|}
\hline Categorias Metodológicas & \\
\hline Editorial & $\begin{array}{l}\text { Seção escrita por editor ou editora de periódico com relevância teórica na } \\
\text { área da Psicologia Evolucionista. }\end{array}$ \\
\hline Estudos Transversais-Correlacionais & $\begin{array}{l}\text { Coleta padronizada em um grupo de pessoas, geralmente por meio de } \\
\text { escalas, questionários ou entrevistas estruturadas. }\end{array}$ \\
\hline Estudos Observacionais & $\begin{array}{l}\text { Estudos envolvendo coleta de dados por observações diretas e não- } \\
\text { participantes. }\end{array}$ \\
\hline Estudo de Casos Múltiplos & $\begin{array}{l}\text { Estudos de fatos particulares, com um caráter idiográfico e descritivo. } 0 \\
\text { foco é a dinâmica de comportamento e seu contexto. }\end{array}$ \\
\hline Estudos Quase-Experimentais & $\begin{array}{l}\text { Estudos metodológicos envolvendo o controle da(s) variável(is) } \\
\text { independente(s), mas sem alocação aleatória dos indivíduos. }\end{array}$ \\
\hline Estudos experimentais & $\begin{array}{l}\text { Estudos envolvendo distribuição aleatória dos sujeitos e controle } \\
\text { metodológico da variável(is) independente(s). }\end{array}$ \\
\hline Resenha de livro & Breve apreciação crítica de livro. \\
\hline Revisões Sistemáticas & $\begin{array}{l}\text { Revisão da literatura que apresenta a descrição dos procedimentos } \\
\text { utilizados para localizar os estudos alvo. }\end{array}$ \\
\hline Revisões Não- Sistemáticas & $\begin{array}{l}\text { Revisão da literatura sem uma descrição dos procedimentos utilizados } \\
\text { para localizar os estudos alvo. }\end{array}$ \\
\hline
\end{tabular}

Tabela 2 - Categorias Temáticas Elaboradas para Classificação dos Estudos

\begin{tabular}{|c|c|}
\hline Categorias Temáticas & \\
\hline Psicologia e Biologia Evolucionista & $\begin{array}{l}\text { Inclui palavras que remetiam à própria área da psicologia evolucionista, ou a } \\
\text { expressões pertencentes à abordagem evolucionista em geral. Dessa forma, } \\
\text { essas palavras-chave eram usadas para delimitar a perspectiva teórica ao qual } \\
\text { o estudo se filiava. Por exemplo: etologia humana, psicologia evolucionária, } \\
\text { adaptação biológica, filogênese, evolução. }\end{array}$ \\
\hline Sexualidade & $\begin{array}{l}\text { Estudos que tinham como um dos focos questões relacionadas às diferenças } \\
\text { entre sexos, seleção sexual e investimento parental. Por exemplo: } \\
\text { comportamento reprodutivo, escolha de parceiros e infidelidade. }\end{array}$ \\
\hline Cultura e Comportamento Grupal & $\begin{array}{l}\text { Engloba palavras-chave referentes a fenômenos sociais em um nível mais } \\
\text { macro, como aspectos culturais diversos, formas de organização da sociedade }\end{array}$ \\
\hline
\end{tabular}


estratificação social, cultura e sociologia.

Contém palavras que remetem ao comportamento e a crenças parentais em

Parentalidade geral e aos cuidados maternos e paternos especificamente, como: cuidado paterno, investimento materno, interação mãe-bebê e pai.

Inclui palavras relacionadas ao fenômeno da cooperação e aos dilemas

Teoria dos Jogos e Cooperação Social envolvidos no interjogo cooperação-competição. Por exemplo: trapaceiros, cooperação, teoria dos jogos.

Emoções

Desenvolvimento Ontogenético

Cognição e Funcionamento Mental

Personalidade

Brincar

Comportamento animal

Princípios gerais do comportamento humano

Psicanálise

Epistemologia

Outros
Abarca palavras que se relacionam com expressões emocionais e de sentimentos, como: sorriso, expressões faciais, ciúmes, e afetividade.

Palavras que faziam menção a fenômenos desenvolvimentais diversos, à psicologia infantil e do desenvolvimento. Por exemplo: apego, aprendizagem, infância, educação, Psicologia do Desenvolvimento Evolucionista.

Incluí palavras que remetem a mecanismos psicológicos, a características estruturais e de funcionamento da mente humana e a áreas do conhecimento específicas sobre esta temática. Por exemplo: cognição, modularidade, linguagem e neurociências.

Palavras que se referem a patologias e transtornos psicológicos diversos, bem como a áreas do conhecimento específicas sobre esta temática. Por exemplo: autismo, psicopatologia evolucionista e transtorno obsessivo compulsivo.

Engloba palavras que se relacionam a diferenças individuais de personalidade. Por exemplo: personalidade, coping e abertura a experiências

Palavras relativas ao comportamento de brincar. São elas: a própria palavra brincar e brincadeira(s).

Palavras que remetem a animais e seu comportamento, como: aranhas, golfinhos, comportamento animal.

Contém palavras gerais sobre o comportamento do ser humano e áreas do conhecimento específicas sobre esta temática, por exemplo: ação, comportamento e análise comportamental.

Palavras que pertencem a essa área de conhecimento. São elas: teoria freudiana e a própria palavra psicanálise.

Palavras que remetem a comportamentos ou fenômenos ligados à manifestação de agressividade ou conduta antissocial. Por exemplo: violência, estupro e comportamento antissocial.

Palavras que pertencem a formas de conhecimento, como por exemplo: pesquisa, conceitos, filosofia e epistemologia

Palavras que apareceram em menor frequência e não se enquadravam nas demais categorias. Por exemplo: restrição de orçamento, crítica de dança e mimese. 


\section{Resultados}

Os resultados foram organizados em dois principais tópicos. No primeiro, foi realizada uma comparação entre a produção nacional e a internacional de artigos, em relação à sua frequência de publicação ao longo dos anos. Em um segundo momento, restringiuse à produção nacional visando a caracterizar a natureza metodológica dos estudos, bem como suas temáticas principais. Foram encontrados 2182 artigos na base de dados internacional, e 46 artigos e 45 teses e dissertações nas bases de dados brasileiras.

\section{Produção internacional e nacional ao longo dos anos}

A partir da base internacional PsycINFO, verificou-se que a publicação mais antiga foi um trabalho de 1894. Até a década de 1950, foram publicados 42 trabalhos distribuídos de forma equilibrada ao longo dos anos (um ou dois trabalhos por ano). Esse número não aumentou até o final dos anos 1980, como pode ser visualizado na Figura 1. Esse número não aumentou até o final dos anos 1980. A partir da década de 1990, observou-se um discreto aumento no número de trabalhos publicados por ano, iniciando com sete trabalhos no ano de 1990, e chegando a 27 trabalhos no ano de 1999. A publicação anual de artigos a partir do ano 2000 cresceu consideravelmente, embora não de forma perfeitamente linear. Dois saltos de produção podem ser destacados: de 2002 (65 artigos) para 2003 (144 artigos), e de 2005 (161 artigos) para 2006 (272 artigos).

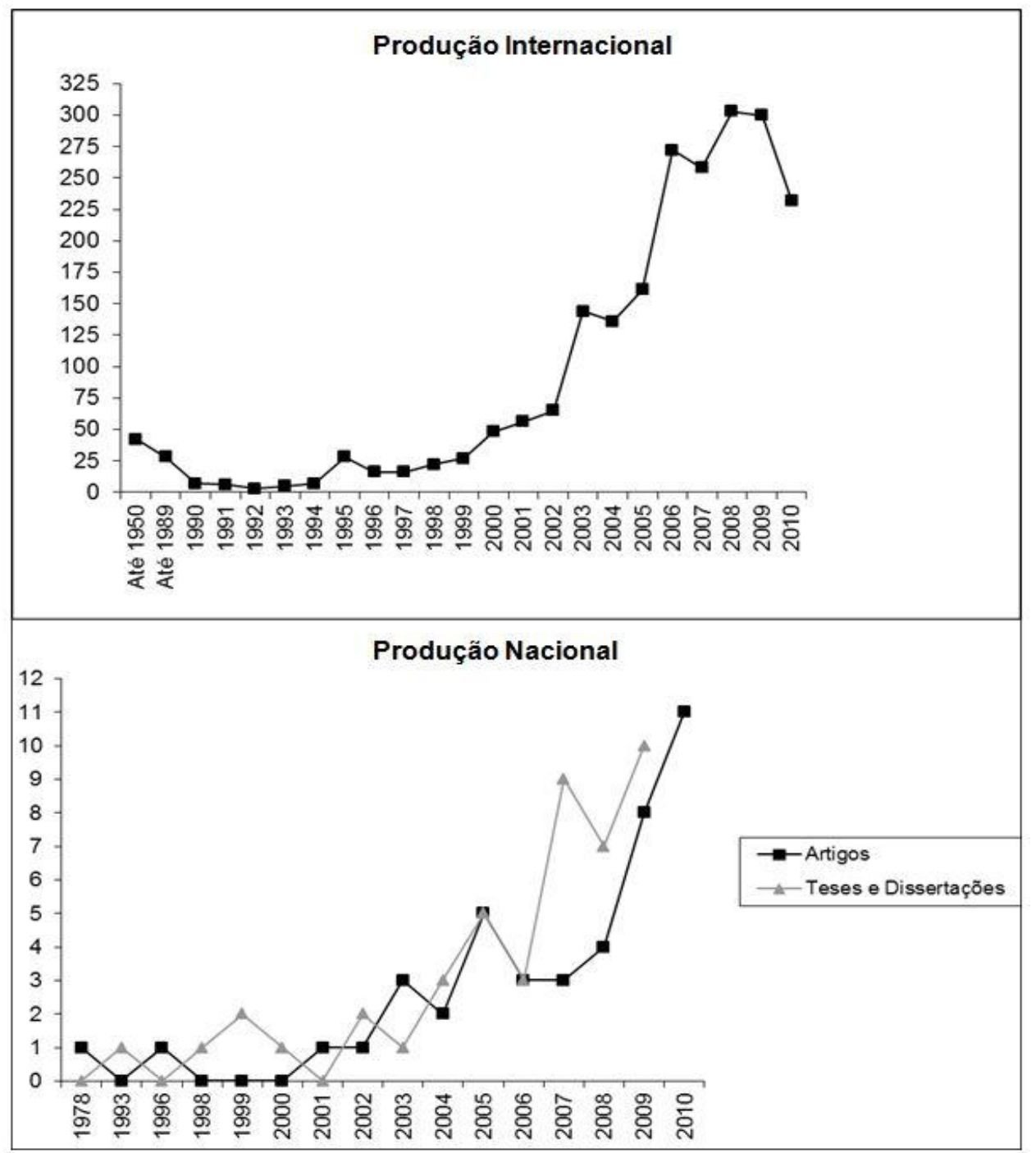

Figura 1 - Frequência de estudos internacionais e nacionais ao longo dos anos. 
Por sua vez, o primeiro artigo científico brasileiro localizado foi publicado em 1978. O artigo, de autoria de Luís Cláudio Figueiredo, apresentou algumas aproximações da Teoria da Evolução darwiniana à Psicologia, principalmente o uso do conceito de seleção natural como um modelo explicativo do comportamento e do fenômeno da aprendizagem (Figueiredo, 1978). Além desse trabalho, foi publicado somente mais um artigo no século passado, no ano de 1996 (Figura 1), no qual Rosana Tokumaru apresentou alguns aspectos da Psicologia Evolucionista por meio de uma resenha do livro "O Animal Moral", de Robert Wright (1996). Assim como na produção internacional, embora em proporção bastante menor, a partir do início de século 21 , verificou-se um aumento na produção de artigos nacionais; destacando-se constantes incrementos na produção a partir do ano de 2007 e o número máximo de artigos em 2010 (11 artigos). No que se refere à produção de teses e dissertações, o primeiro trabalho foi defendido no ano de 1993. Trabalhos isolados foram publicados até o ano de 2003, ocorrendo um aumento a partir de 2004 (três trabalhos) até 2009 (10 trabalhos).

\section{Natureza metodológica e temática dos trabalhos nacionais}

A classificação das temáticas foi realizada através das palavras-chave dos trabalhos (159 palavras-chave para artigos e 139 palavras-chave para teses e dissertações). Dessa forma, um mesmo estudo poderia ser classificado em mais de uma temática, dependendo da natureza de suas palavraschave. Como pode ser visto na Tabela 3 , houve maior concentração de palavras relacionadas ao tema "Psicologia Evolucionista e Biologia", tanto entre os artigos (28\% das palavras-chave), quanto entre as teses e dissertações $(27,5 \%$ das palavras-chave). Nesse tema, foram incluídos principalmente estudos que tinham como objetivo apresentar a visão da Psicologia Evolucionista sobre fenômenos específicos. Exemplos são o estudo de Carvalho (2008), em que se apresentaram as contribuições da área para a compreensão da linguagem; e o estudo de Fiaes e Bichara (2009), em que se mostrou uma visão da Psicologia Evolucionista sobre o brincar em crianças autistas. Além desses estudos, foram também incluídos nessa temática aqueles que tinham como objetivo apresentar os pressupostos da teoria ou compará-los com outras abordagens (e.g., Lopes \& Vasconcellos, 2008). Destaca-se que a maior parte desses trabalhos foram de natureza de revisão não-sistemática de literatura.

A temática da sexualidade, por sua vez, foi a segunda mais frequente entre as palavraschave dos artigos (16\%) e das teses e dissertações (15\%), sendo incluídos nessa categoria estudos que discorreram sobre as contribuições da seleção sexual para a compreensão de fenômenos psicológicos, bem como estudos que testaram hipóteses baseadas na teoria da seleção sexual (e.g., Spinelli, Hattori, \& Souza, 2010). Outros estudos dessa temática envolveram a relação entre estratégias reprodutivas e investimento parental (e.g., Borrione \& Lordelo, 2005), bem como as diferenças sexuais em relação a fenômenos diversos (e.g., Hansen et al., 2007).

Estudos cujas palavras-chave foram classificadas nas temáticas Parentalidade, Desenvolvimento Ontogenético e Brincar representaram, conjuntamente, $15,5 \%$ do total de palavras-chave de artigos, e a mesma porcentagem de palavras-chave das teses e dissertações. É pertinente discuti-los de forma conjunta, uma vez que todos estão relacionados à temática do Desenvolvimento Humano, embora as palavras-chave classificadas como "Desenvolvimento Ontogenético" sejam mais gerais (como infância e aprendizagem). Enquanto isso, as palavras das outras duas categorias são mais específicas ao fenômeno da parentalidade e do brincar. Exemplos dos estudos com tais palavras-chave são o de Lordelo, Rocha e Bichara (2009), sobre as funções da imaturidade e sua relevância para a Educação Infantil; o de Manfroi, Macarini e Vieira (2011), sobre o papel do pai no desenvolvimento infantil; e o de Menezes et al. (2010) a respeito das diferenças de gênero no brincar de crianças em idade escolar. 
Tabela 3 - Métodos de Investigação dos Estudos Nacionais e Temas de Investigação em Estudos Nacionais

\begin{tabular}{|c|c|c|c|c|c|}
\hline \multirow{3}{*}{ Métodos de Investigação } & \multicolumn{2}{|l|}{ Artigos } & \multicolumn{2}{|c|}{ Teses e Dissertações } & \multirow[b]{3}{*}{ Total } \\
\hline & \multicolumn{2}{|l|}{$n=46$} & \multicolumn{2}{|c|}{$n=45$} & \\
\hline & Frequência & $\%$ & Frequência & $\%$ & \\
\hline Revisões não-sistemáticas da literatura & 34 & 74,0 & 13 & 29,0 & 47 \\
\hline Estudos transversais-correlacionais & 2 & 4,5 & 22 & 49,0 & 24 \\
\hline Revisões sistemáticas da literatura & 3 & 6,5 & 3 & 7,0 & 6 \\
\hline Estudos observacionais & 4 & 9,0 & 1 & 2 & 5 \\
\hline Estudos de casos múltiplos & 0 & 0 & 3 & 7,0 & 3 \\
\hline Estudos quase-experimentais & 1 & 2 & 1 & 2 & 2 \\
\hline Resenha de livro & 1 & 2 & 1 & 2 & 2 \\
\hline Estudos experimentais & 0 & 0 & 1 & 2 & 1 \\
\hline Editorial & 1 & 2 & 0 & 0 & 1 \\
\hline \multirow[t]{2}{*}{ Temas de Investigação } & \multicolumn{2}{|l|}{ Artigos } & \multicolumn{2}{|c|}{ Teses e Dissertações } & \\
\hline & Frequência & $\%$ & Frequência & $\%$ & Total \\
\hline Psicologia Evolucionista e Biologia & 45 & 28 & 38 & 27,5 & 83 \\
\hline Sexualidade & 26 & 16 & 21 & 15 & 47 \\
\hline Cultura e comportamento grupal & 14 & 9 & 18 & 13 & 32 \\
\hline Cognição e funcionamento mental & 12 & 7,5 & 14 & 10 & 26 \\
\hline Parentalidade & 10 & 6 & 11 & 8 & 21 \\
\hline Desenvolvimento Ontogenético & 11 & 7 & 7 & 5 & 19 \\
\hline Teoria dos Jogos e cooperação social & 9 & 6 & 0 & 0 & 9 \\
\hline Emoções & 9 & 6 & 0 & 0 & 9 \\
\hline Comportamento antissocial & 2 & 1 & 7 & 5 & 9 \\
\hline Psicopatologia & 6 & 4 & 2 & 1 & 8 \\
\hline Brincar & 4 & 2,5 & 3 & 2,5 & 6 \\
\hline Princípios gerais do comportamento humano & 3 & 2 & 3 & 2 & 6 \\
\hline Epistemologia & 1 & 0,5 & 5 & 3,5 & 6 \\
\hline Comportamento animal & 4 & 2,5 & 0 & 0 & 4 \\
\hline Psicanálise & 3 & 2 & 1 & 1 & 4 \\
\hline Personalidade & 0 & 0 & 3 & 2 & 3 \\
\hline Outros & 0 & 0 & 6 & 4 & 6 \\
\hline Total de palavras-chave & 159 & & 139 & & \\
\hline
\end{tabular}

Ainda, nove por cento das palavraschave dos artigos e $13 \%$ das palavras-chave de teses e dissertações foram relacionadas à temática da cultura e do comportamento grupal. Os estudos tiveram como foco, por exemplo, as contribuições da Psicologia Evolucionista para a definição do conceito de cultura (Lordelo, 2010) e a discussão sobre as implicações do fenômeno da categorização de grupo na violência e identificação de raça (Gonçalves, 2010).

Vale também destacar os trabalhos que tiveram como palavras-chave a temática da cognição e do funcionamento mental $(7,5 \% \mathrm{em}$ artigos e $10 \%$ em teses e dissertações).
Tais publicações, em sua maioria, são estudos teóricos sobre a concepção de mente e cognição da Psicologia Evolucionista (e.g., Moura, 2005), embora também tenha havido estudos empíricos que focalizaram o funcionamento mental de grupos específicos, como as crianças autistas (Fiaes \& Bichara, 2009).

Por fim, outras temáticas também estiveram representadas pelas palavras-chave, porém em menor frequência. São exemplos dessas temáticas: a Teoria dos Jogos e a cooperação social, as emoções e o comportamento antissocial. 


\section{Discussão}

De maneira geral, a revisão da literatura indicou que a produção nacional na área da PE vem acompanhando o crescimento verificado também na produção internacional, embora em uma proporção bastante menor. Tanto no Brasil, quanto no exterior, verificouse um importante aumento na produção a partir do século XXI, sendo que, no âmbito internacional, houve um crescimento já nos primeiros cinco anos do século e, no Brasil, no final de sua primeira década.

O salto na produção a partir dos anos 2000 pode estar relacionado à publicação de importantes livros que contribuíram para a divulgação das ideias da PE no Brasil e no mundo. Por exemplo, alguns livros de Steven Pinker, tais como "Como a mente funciona" (Pinker, 1998) e "Tábula Rasa" (Pinker, 2004) permitiram uma sistematização dos principais pressupostos da PE, apresentados em uma linguagem acessível a diferentes áreas do conhecimento. Com propósito semelhante, outros livros foram publicados nessa mesma época, tais como "Mãe Natureza: Uma visão feminina da evolução" (Hrdy, 2001), que aborda a visão da PE sobre a maternidade; "O que nos faz humanos: genes, natureza $\mathrm{e}$ experiência" (Ridley, 2004), que discute a dicotomia "inato × aprendido"; e "A Paixão Perigosa: Por que o ciúme é tão necessário quanto o amor e o sexo" (Buss, 2000), o qual apresenta ideias da PE sobre fenômenos ligados à sexualidade humana.

Pode-se dizer que a PE teve seu marco inicial com a publicação da obra "The Adapted Mind: Evolutionary psychology and the generation of culture" (Barkow, Cosmides, \& Tooby, 1992) há 20 anos, mas somente nos últimos 10 anos ela tem sido divulgada com maior amplitude. É justificável, portanto, que a maior parte da produção na área esteja relacionada a esse período mais recente. Essas publicações, em conjunto, parecem ter permitido uma inserção da $\mathrm{PE}$ em diferentes subáreas da Psicologia, tais como a Psicologia do Desenvolvimento, Psicologia Cognitiva, Sexualidade; gerando uma série de hipóteses a serem testadas empiricamente.

No contexto brasileiro, entretanto, parece ter havido uma resistência à entrada da $\mathrm{PE}$ como campo de investigação. Ou, no mínimo, há uma maior lentidão em acompanhar a produção científica dessa abordagem. Talvez isso esteja relacionado a características específicas da Psicologia no país que, acompanhando tendências sociais e políticas marcantes no final do século passado, procurou fugir de perspectivas teóricas que, supostamente, impedissem o exercício da liberdade e da igualdade humana. Por exemplo, vale mencionar o radicalismo dialético, que também impôs obstáculos ao desenvolvimento da avaliação psicológica no Brasil (Noronha \& Reppold, 2010). Hoje, porém, a PE tem sido utilizada, inclusive, como base para um pensamento ético que pressupõe que o que nos faz humanos é a possibilidade de, ao mesmo tempo, sermos iguais enquanto espécie, mas únicos enquanto seres vivos que lutam por sobreviver em ambientes muito distintos (Pinker, 2004).

A dificuldade de expansão das ideias da PE no país pode também estar relacionada à natureza metodológica dos estudos encontrados na literatura brasileira. Em sua maioria, os estudos nacionais encontrados foram revisões não-sistemáticas da literatura, que tinham como objetivo apenas apresentar as ideias da PE relacionadas a diferentes temas. Dessa forma, é plausível pensar que tais revisões teóricas estejam vinculadas a uma tentativa de divulgar as contribuições da área, de modo a desmistificá-las e torná-las mais aceitas pela Psicologia de maneira geral. Ao mesmo tempo, essas publicações apontam para uma fase inicial da pesquisa em PE no Brasil, ainda bastante calcada na organização teórica e pouco na exploração empírica de hipóteses.

No que diz respeito às temáticas dos artigos, teses e dissertações brasileiros, constatou-se um predomínio de palavras-chave que remetiam à perspectiva teórica à qual $\mathrm{o}$ trabalho se filiava, no caso, à PE. A prevalência dessa temática entre as palavras-chave pode estar relacionada ao predomínio de estudos de revisões não-sistemáticas, que tinham como objetivo justamente apresentar a visão da PE sobre diversos fenômenos. Além disso, a inclusão dessas palavras-chave em si pode ser considerada uma estratégia de divulgação da PE no país, como forma de as produções serem mais facilmente localizadas.

Os dois temas específicos que tiveram maior expressão entre os estudos foram o da sexualidade e dos diferentes aspectos relacionados ao desenvolvimento humano (parentalidade, brincar, desenvolvimento ontogenético). Talvez essa maior expressão se 
deva ao fato de que ambos os temas são considerados clássicos na $\mathrm{PE}$. A sexualidade (incluindo questões reprodutivas e diferenças entre sexos) é um fenômeno central na compreensão da evolução da espécie humana e, através de conceitos clássicos, como o de "seleção sexual", é foco de interesse desde Darwin. Por outro lado, o estudo do desenvolvimento humano também é de interesse especial na PE, uma vez que permite uma melhor compreensão da interação entre as causas distais e proximais.

Ressalta-se ainda que uma ênfase nesses dois temas pode também estar relacionada ao foco de interesse dos pesquisadores do Grupo de Trabalho em PE da ANPPEP. Esse grupo, no ano de 2006, deu início a um projeto nacional de pesquisa intitulado "O moderno e o ancestral: a contribuição da Psicologia Evolucionista para a compreensão dos padrões reprodutivos e de investimento parental humano". Portanto, conforme o título, os dois focos de interesse principais do estudo foram a sexualidade e a parentalidade humana, refletindo um aumento na produção de estudos teóricos e empíricos sobre essas temáticas e, consequentemente, um crescimento como um todo na produção brasileira na área.

\section{Considerações Finais}

$\mathrm{A}$ produção nacional em $\mathrm{PE}$, comparada à mundial, mostra-se seguindo a tendência de expansão ao longo dos anos, sobretudo na última década. Ainda que em uma crescente, salienta-se a carência, no Brasil, de estudos empíricos ancorados na PE. Vale ressaltar, todavia, que a revisão de literatura relatada no presente manuscrito não reflete completamente a produção brasileira na área, haja vista que diversos pesquisadores também têm publicado seus estudos em periódicos internacionais. Portanto, embora o foco deste artigo tenha sido a caracterização das publicações em periódicos nacionais, é necessário levar em conta que, muito provavelmente, o crescimento de publicações no Brasil também esteja associado a um crescimento de publicações fora do país. Exemplos de publicações dessa natureza são os estudos de Castro e Lopes (2011), sobre escolha de parceiros amorosos, o de Carvalho e Seidl-de-Moura (2011), sobre a empatia entre pais e filhos, o estudo de Alencar, Siqueira e
Yamamoto (2008), sobre a cooperação entre crianças, e o de Souza, Verderane, Taira e Otta (2006), acerca do ciúme.

Finalmente, a partir das lacunas verificadas na produção nacional, enfatiza-se que se consideram contribuições inovadoras e relevantes, tanto nacional, quanto mundialmente, estudos que investiguem diferenças individuais. Áreas como a personalidade e a psicopatologia encontram-se desfalcadas de produção nacional a partir da perspectiva Evolucionista. Essas áreas, no entanto, são responsáveis por estabelecer um elo teórico entre as perspectivas que abordam aspectos universais da espécie humana, fixados ao longo da evolução, e as perspectivas interessadas em estudar o singular de cada indivíduo. Uma abordagem sobre a personalidade à luz da PE poderia aprofundar o entendimento dos custos e benefícios associados a diversos padrões comportamentais que levam ao ajuste ou desajuste social nos tempos atuais.

\section{Referências}

Alencar, A., Siqueira, J. O., \& Yamamoto, M. E. (2008). Does group size matter? Cheating and cooperation in Brazilian school children? Evolution and Human Behavior, 29, 42-48.

Barkow, J. H., Cosmides, L., \& Tooby, J. (1992). The adapted mind: Evolutionary psychology and the generation of culture. New York: Oxford University Press.

Borrione, R. T. M., Lordelo, E. R. (2005). Escolha de parceiros sexuais e investimento parental: uma perspectiva desenvolvimental. Interação em Psicologia, 9(1), 35-43.

Buss, D. M. (1995). Evolutionary Psychology: A new paradigm for psychological science. Psychological Inquiry, 6(1), 1-30.

Buss, D. M. (2000). A paixão perigosa. Por que o ciúme é tão necessário quanto o amor e o sexo. Rio de Janeiro: Objetiva.

Carvalho, F. O. (2008). Psicologia evolucionista e a seleção sexual: o caso da linguagem. Psicologia: Teoria e Pesquisa, 24(1), 77-86. 
Carvalho, R. V. C., \& Seidl-de-Moura, M. L. (2011). Empathic interactions between parents and children: an exploratory study. The Romanian Journal of Psychology, Psychotherapy and Neuroscience, 1, 192214.

Castro, F. N., \& Lopes, F. A. (2011). Romantic Preferences in Brazilian Undergraduate Students: From the Short Term to the Long Term. The Journal of Sex Research, 48, 479-485.

Darwin, C. (1859/2010). A origem das espécies. São Paulo: Folha de São Paulo.

Darwin, C. (1872/2009). A expressão emoções no homem e nos animais. São Paulo: Companhia de Bolso.

Fiaes, C. S., \& Bichara, I. D. (2009). Brincadeiras de faz-de-conta em crianças autistas: limites e possibilidades numa perspectiva evolucionista. Estudos de Psicologia (Natal), 14(3), 231-238.

Figueiredo, L. C. M. (1978). Alguns reflexos da teoria da evolução no desenvolvimento da Psicologia como ciência biológica. Psicologia, 4(3), 19-37.

Gonçalves, D. M. (2010). Violência e identificação de raça como consequência da categorização de grupo. Estudos de Psicologia, 15(1), 97-102.

Hansen, J., Macarini, S. M., Martins, G. D. F., Wanderlind, F. H., \& Vieira, M. L. (2007). $\mathrm{O}$ brincar e suas implicações para o desenvolvimento infantil a partir da Psicologia Evolucionista. Revista Brasileira Crescimento e Desenvolvimento Humano, 17(2), 133-143.

Hrdy, S. B. (2001). Mãe Natureza: uma visão feminina da evolução: maternidade, filhos e seleção natural. Rio de Janeiro, RJ: Campus.

Izar, P. (2009). Ambiente de adaptação evolutiva. In E. Otta, \& M. E. Yamamoto (Eds.), Psicologia Evolucionista (pp. 2232). Rio de Janeiro: Guanabara Koogan.

Laland, K. N., \& Brown, G. R. (2002). Sense and Nonsense: Evolutionary Perspectives on Human Behaviour. New York: Oxford University Press.
Lopes, R. G., \& Vasconcellos, S. (2008). Implicações da teoria da evolução para a psicologia: a perspectiva da psicologia evolucionista. Estudos de Psicologia, 25(1), 123-30.

Lordelo, E. R. (2010). A psicologia evolucionista e o conceito de cultura. Estudos de Psicologia, 15(1), 55-62.

Lordelo, E. Rocha, \& Bichara, I. D. (2009). Revisitando as funções da imaturidade: uma reflexão sobre a relevância do conceito na Educação Infantil. Psicologia USP, 20(3), 337-354.

Manfroi, E. C., Macarini, S. M., \& Vieira, M. L. (2011). Comportamento parental e o papel do pai no desenvolvimento infantil. Revista Brasileira de Crescimento e Desenvolvimento Humano, 21(1), 59-69.

Marx, M. H., \& Hillix, W. A. (2000). Sistemas e teorias em psicologia (11. ed.). São Paulo: Cultrix.

Menezes, A. B. C., Brito, R. C. S., Figueira, R. A., Bentes, T. F., Monteiro, E. F., \& Santos, M. C. (2010). Compreendendo as diferenças de gênero a partir de interações livres no contexto escolar. Estudos de Psicologia, 15(1), 79-87.

Moura, M. L. S. (2005). Dentro e fora da caixa preta: a mente sob um olhar evolucionista. Psicologia: Teoria e Pesquisa, 21(2), 141147.

Noronha, A. P. P., \& Reppold, C. T. (2010). Considerações sobre a avaliação psicológica no Brasil. Psicologia: Ciência e Profissão, 30(núm. esp.), 192-201.

Otta, E., \& M. E. Yamamoto (2009). Psicologia Evolucionista. Rio de Janeiro: Guanabara Koogan.

Pinker, S. A. (1998). Como a mente funciona. São Paulo: Companhia das Letras.

Pinker, S. A. (2004). Tábula Rasa: A negação contemporânea da natureza humana. São Paulo: Companhia das Letras.

Ridley, M. (2004). O que nos faz humanos. Genes, natureza e experiência. Rio de Janeiro: Record. 
Rodrigues, M. M. P. (2009). Evolução humana. In E. Otta, \& M. E. Yamamoto (Eds.), Psicologia Evolucionista (pp. 33-53). Rio de Janeiro: Guanabara Koogan.

Santos, I. B. C., \& Varella, M. A. C. (2007). A era dos mal-entendidos. Revista Psique, Especial, 14-21.

Spinelli, L. H. P, Hattori, W. T, \& Souza, M. B. C (2010). Why do women not prefer much older men? A hypothesis based on alterations in male reproductive physiology related to increased age. Estudos de Psicologia (Natal), 15(1), 119-123.

Souza, A. A. L., Verderane, M. P., Taira, J. T., \& Otta, E. (2006). Emotional and sexual jealousy as a function of sex and sexual orientation in a brazilian sample. Psychological Reports, Nebraska, 98, 529535.

Tokumaru, R. S. (1996). Moral da história? Estudos de Psicologia, 2(1), 205-208.
Tooby, J., \& Cosmides, L. (1992). The psychological foundations of culture. In J. H. Barkow, L. Cosmides, \& J. Tooby (Eds.), The adapted mind: Evolutionary psychology and the generation of culture (pp. 19-136). New York: Oxford University Press.

Wright, R. (1996). O animal moral. Por que somos como somos: a nova ciência da psicologia evolucionista. São Paulo: Editora Campus.

Yamamoto, M. E. (2009). Introdução: aspectos históricos. In E. Otta, \& M. E. Yamamoto (Eds.), Psicologia Evolucionista (pp. 3-9). Rio de Janeiro: Guanabara Koogan.

Yamamoto, M. E., \& Seild-de-Moura, M. L. (2010). A Psicologia Evolucionista no Brasil. Estudos de Psicologia (Natal),15(1), 53-54.

Recebido em 31 de Maio de 2012 Texto reformulado em 17 de Outubro de 2012 Aceite em 22 de Outubro de 2012 Publicado em 31 de Dezembro de 2012 